\title{
ADSORBATE-INDUCED RESTRUCTURING OF THE Fe(100) SURFACE: MODEL CLUSTER STUDIES
}

\author{
W. ArabczyK \\ Technical University of Szczecin, Institute of Chemical Technology \\ Pułaskiego 10, 70-322 Szczecin, Poland \\ E. RAUSCIE AND F. STORBECK \\ Sektion Physik, Technische Universität Dresden \\ Mommsenstraße 13, O-8027 Dresden, Germany
}

(Received May 2, 1991)

The Extended Hückel Theory (EHT) has been used to calculate the energy of iron clusters, $\mathrm{Fe}_{13}$, modelling an $\mathrm{Fe}(100)$ surface, as well as the energy of iron clusters with oxygen, $\mathrm{Fe}_{13}-\mathrm{O}$; nitrogen, $\mathrm{Fe}_{13}-\mathrm{N}$, or carbon atom, $\mathrm{Fe}_{13}-\mathrm{C}$, adsorbed on a reconstructed/non-reconstructed surface. In order to determine the relative positions of iron atoms and of the adsorbed atom a sphere model was employed assuming displacement of only one iron atom.

PACS numbers: 71.45.Nt, 68.45.Da, 68.55.Jk

\section{Introduction}

The phenomenon of reconstruction on clean semiconductor faces and transition metal crystals has been described earlier. Review of the results of experimental and theoretical study on that issue is presented in Ref. [1]. Moreover, adsorbed atoms and molecules can frequently cause restructuring of crystal surfaces, ranging from small atomic relaxations to macroscopic shape modifications [2-4]. Good examples of the interlayer space relaxation are provided by atomic adsorption on nickel surface. Clean surfaces typically exhibit contractions in the topmost interlayer spacing relatively to the bulk value. Upon adsorption, these contractions are reduced and often become undistinguishable from the bulk value [5]. Low energy electron diffraction (LEED) analysis for $\mathrm{Ni}(111)-(2 \times 2) \mathrm{O}[6]$ and $\mathrm{Ni}(110)-(2 \times 1) \mathrm{O}$ [7] structures evidence an oxygen-induced relaxation with nickel atoms displacing not only vertically but also laterally. Some assumptions were made for the adsorption systems as to insertion of the adsorbate below the uppermost layer, e.g. 
for nitrogen [8] and oxygen [9] on titanium, nitrogen on tungsten [10], oxygen on nickel [11].

In Ref. [12] an arrangement was suggested in which one nitrogen atom is located above and one below the uppermost iron layer. For carbon on $\mathrm{Fe}(111)$ surface similar suggestions were made [13].

To make the adsorption states and processes better understood, cluster approximation was often employed. The effective medium approach (EMA) was used to calculate the total ground state potential energy of the system consisting of an oxygen atom outside or inside the $\mathrm{Ni}(100)$ or (111) surface [11]. The EMA was also used to describe relaxation of iron (100) surface due to adsorption of a nitrogen atom in a fourfold site [14]. Ab initio calculations indicate that oxygen in a fourfold site presents lowest energy configuration too [15-17], thus confirming the experimental results obtained with LEED [18] and LEIS (low energy ion scattering) [19] methods. EIIT calculations show that a hollow in the non-reconstructed $\mathrm{Fe}(111)$ surface is the most preferential site for oxygen adsorption. For nitrogen or carbon, a hollow under the iron atom is preferred [20,21]. In this paper, we are trying to interpret and discuss by means of the EHT method the surface reconstruction exemplified by the adsorption of oxygen, nitrogen, or carbon on the iron (100) surface.

\section{Calculations and results}

The EHT method [22] was used to calculate the total energy of clusters. The advantage of its short computation time is unfortunately compensated for by the disadvantage of drastic approximations making some absolute values dubious, e.g. those of binding energies and equilibrium distances. However, a big similarity between the clusters considered, that differ only in their atomic positions, makes it possible to use this method to compare the cluster energies and accordingly to conclude which of the adsorption states is more likely. The cluster to be calculated was assumed to consist of 13 iron atoms. Reconstruction of the surface due to the insertion of an adsorbate atom was desired to be limited to one iron atom displacement only, with all other atoms remaining in their initial positions. Most significant dislocation occurred as the adsorbate atom and its three neighbouring iron atoms were placed coplanar. When the adsorbate atom was located below the first layer, the iron atom displacement was smaller. The atomic radius values as in Ref. [21] were taken for calculation.

On the basis of the above.simplifying assumptions, atomic coordinates were determined for the iron (100) surface, as well as for adsorbate above and below the uppermost layer and in the state of maximum reconstruction (see Table $I$ and Fig. 1). Locations of the "movable" iron atom are denoted by $\mathrm{Fe}^{\circ}$ (solid line), $\mathrm{Fe}^{\mathrm{u}}$ (broken line), and $\mathrm{Fe}^{*}$ (dotted line).

The results are presented in Table II, and also pictured graphically' in Fig. 2. In the latter, the difference between the cluster energy for the adsorption states on a reconstructed surface and that for a non-reconstructed one is marked in the ordinate. In the abscissa, there are distances of the "movable" atoms centres perpendicularly to the surface. The surface considered has been a plane fixed by 
TABLE I

Coordinates for $\mathrm{Fe}$ and $\mathrm{Fe}-\mathrm{X}$ clusters on the $(100)$ surface $(X=N, O, C)$

\begin{tabular}{c|r|r|r}
\hline \hline Atom & \multicolumn{1}{|c|}{$x[\mathrm{~nm}]$} & \multicolumn{1}{c}{$y[\mathrm{~nm}]$} & $z[\mathrm{~nm}]$ \\
\hline $\mathrm{X}^{\circ}$ & -0.1433 & -0.1433 & 0.0408 \\
$\mathrm{X}^{*}$ & -0.1097 & -0.0243 & -0.0137 \\
$\mathrm{X}^{\mathrm{u}}$ & -0.1121 & 0.0000 & -0.0405 \\
$\mathrm{Fe}^{0}$ & 0.0000 & 0.0000 & 0.0000 \\
$\mathrm{Fe}^{*}$ & 0.0465 & 0.0300 & 0.0552 \\
$\mathrm{Fe}^{\mathrm{u}}$ & 0.0434 & 0.0182 & 0.0464 \\
$\mathrm{Fe}_{2}$ & 0.2866 & 0.0000 & 0.0000 \\
$\mathrm{Fe}_{3}$ & -0.2866 & 0.0000 & 0.0000 \\
$\mathrm{Fe}_{4}$ & 0.0000 & 0.2866 & 0.0000 \\
$\mathrm{Fe}_{5}$ & 0.0000 & -0.2866 & 0.0000 \\
$\mathrm{Fe}_{6}$ & 0.2866 & 0.2866 & 0.0000 \\
$\mathrm{Fe}_{7}$ & -0.2866 & -0.2866 & 0.0000 \\
$\mathrm{Fe}_{8}$ & -0.2866 & 0.2866 & 0.0000 \\
$\mathrm{Fe}_{9}$ & 0.2866 & -0.2866 & 0.0000 \\
$\mathrm{Fe}_{10}$ & 0.1433 & 0.1433 & -0.1433 \\
$\mathrm{Fe}_{11}$ & -0.1433 & -0.1433 & -0.1433 \\
$\mathrm{Fe}_{12}$ & 0.1433 & -0.1433 & -0.1433 \\
$\mathrm{Fe}_{13}$ & -0.1433 & 0.1433 & -0.1433
\end{tabular}

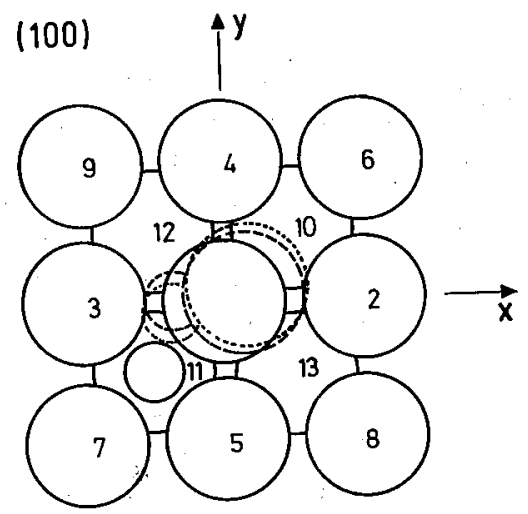

Fig. 1. Top view of a cluster at different adsorption states, denotations as follows: large circles - iron atoms, small circles - adsorbate atoms, overlayer adsorption, - - underlayer adsorption, $\cdots \cdots$ adsorption with the maximal surface reconstruction. 
TABLE II

Energies of $\mathrm{Fe}_{13}, \mathrm{Fe}_{13}-\mathrm{O}, \mathrm{Fe}_{13}-\mathrm{N}, \mathrm{Fe}_{13}-\mathrm{C}$ clusters [eV].

\begin{tabular}{c|r|r|r|r}
\hline & \multicolumn{1}{|c|}{$\mathrm{Fe}_{13}$} & \multicolumn{1}{|c|}{$\mathrm{Fe}_{13}-\mathrm{O}$} & $\mathrm{Fe}_{13}-\mathrm{N}$ & $\mathrm{Fe}_{13}-\mathrm{C}$ \\
\hline Total energy & & & & \\
${ }^{\circ}$ state, $E^{\mathrm{o}}$ & -915.072 & -967.777 & -959.157 & -950.695 \\
${ }^{*}$ state, $E^{*}$ & -915.016 & -967.738 & -959.133 & -950.707 \\
u state, $E^{\mathrm{u}}$ & -915.019 & -967.755 & -959.163 & -950.761 \\
Activation energy & & & & \\
$E^{0 \rightarrow *}$ & & 0.039 & 0.024 & -0.012 \\
$E^{\mathrm{u} \rightarrow *}$ & & -0.017 & 0.030 & -0.054 \\
Translation energy & & & & \\
$E^{\mathrm{o} \rightarrow \mathrm{u}}$ & & 0.022 & -0.006 & -0.066 \\
Reconstruction energy & & & & \\
$E_{\mathrm{R}}^{0 \rightarrow *}$ & 0.056 & & & \\
$E_{\mathrm{R}}^{\mathrm{ou}}$ & 0.053 & & &
\end{tabular}

the iron atoms centres. Potential curves 1,2, and 3 are plots of the cluster energy against distance of the adsorbate atom or of the "movable" iron atom from the surface and deal with the cases of:

1) reconstruction of the iron surface,

2) oxygen, nitrogen, or carbon adsorption above the non-reconstructed uppermost iron layer, and

3) oxygen, nitrogen, or carbon adsorption below the hypothetically reconstructed uppermost layer, respectively.

The calculated points in the potential energy diagram are denoted the same as in Table I. The actual pathways followed are indicated with the thickened segments of the curves.

Through immediate comparison of the magnitude of cluster energies in various states we get the energy change associated with overlayer to underlayer adsorption state transition: $E^{0 \rightarrow \mathrm{u}}=E^{\mathrm{u}}-E^{\mathrm{o}}$, and the activation energy for the transition of an atom adsorbed in a fourfold hollow on the non-reconstructed surface to the underlayer adsorption state $E^{\circ \rightarrow *}=E^{*}-E^{\circ}$, and opposing $E^{\mathrm{u} \rightarrow *}=E^{*}-E^{\mathrm{u}}$.

In each of the cases considered, the activation energy in a transition from the overlayer adsorption to the underlayer adsorption is less than the reconstruction energy. In this process, the number of iron atoms neighbouring the adsorbate atom, i.e. coordination number of the latter increases. The difference between the reconstruction energy $\left(E_{\mathrm{R}}^{\mathrm{o} \rightarrow \mathrm{u}}\right)$ and the energy change in a $X^{\circ}$ to $X^{\mathrm{u}}$ transition $\left(E^{0 \rightarrow u}\right)$ can be attributed to the growing interaction of the adsorbate and iron atoms due to the increase in coordination number $\left(E^{\Delta C}\right)$. Calculations show that this energy value grows when the number of electrons in the adsorbate atom decreases, i.e. $E_{O X Y G E N}^{\triangle C}<E_{\text {NITROGEN }}^{A C}<E_{\text {CARBON }}^{\Delta C}$. This regularity was observed when analysing positions of oxygen, nitrogen, and carbon atoms on the $\mathrm{Fe}(111)$ surface [21]. 


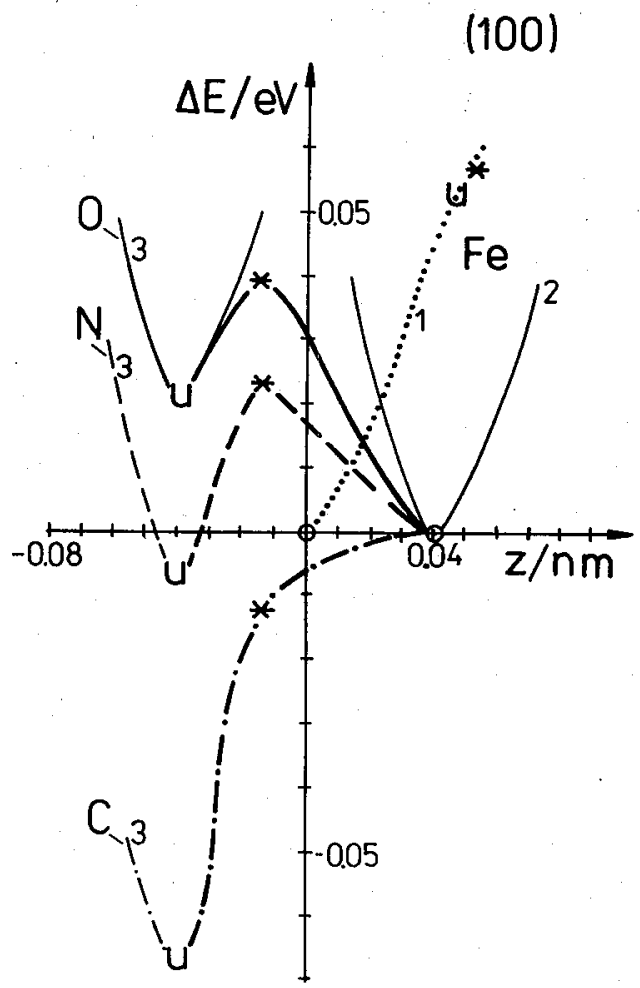

Fig. 2. Potential energy diagram for iron clusters with oxygen, nitrogen, and carbon adsorbed on the $\mathrm{Fe}(100)$ surface (see text).

From the calculations it appears that a fourfold hollow in the non-reconstructed $\mathrm{Fe}(100)$ surface is the most preferential adsorption site for oxygen. Transition to the underlayer adsorption state is an activated process and in terms of energetics seems to be less likely. For carbon adsorption, a hollow under the iron atom is preferred; the transition to such a state from the adsorption on the non-reconstructed surface requires no activation. For nitrogen, the underlayer and overlayer adsorption energies are nearly equal. Transition between these two adsorption states is possible as long as the potential barrier is overcome. This potential, however, is about twice lower than the pure surface reconstruction energy needed for the formation of such a hollow between iron atoms, which would enable displacement of an atom of $0.11 \mathrm{~nm}$ diameter.

\section{Discussion}

Previous LEED study on iron (100) surface covered with carbon or oxygen atoms indicated formation of bidimensional structures, $c(2 \times 2)-\mathrm{C}$ and $c(2 \times 2)-\mathrm{N}$. The ordered carbon structure was obtained by carbon segregation to the sample surface [23], or by thermal decomposition of ethylene [24, 25]. $c(2 \times 2)-\mathrm{N}$ was 
received by segregation [23] or dissociative adsorption of $\mathrm{N}_{2}$ [26], $\mathrm{NH}_{3}$ [27], or $\mathrm{CH}_{3} \mathrm{NHNH}_{2}$ [28]. The oxygen adsorbed on the $\mathrm{Fe}(100)$ surface forms a bidimensional structure, $p(1 \times 1)-\mathrm{O}$. Earlier reports on the existence of $p(2 \times 2)-\mathrm{O}$ structure, besides the former, have not been confirmed by latest study [29]. Dissociative adsorption of $\mathrm{CO}$ on $\mathrm{Fe}(100)$ yields $c(2 \times 2)-\mathrm{C}, \mathrm{O}$ structure [28] that might have been misinterpreted earlier as $c(2 \times 2)-\mathrm{O}$.

In all the models corresponding to the above bidimensional structures, the adsorbatom is located in a fourfold hollow. Previous more precise data obtained from LEED intensity analysis, as well as theoretical consideration confirm the locations of oxygen [15-18] and nitrogen [14-30] atoms. The EHT calculations performed in this study show full accordance in the case of oxygen adsorption. The results for $\mathrm{Fe}_{13}-\mathrm{N}$ cluster indicate close energy values for either atomic position. Regarding all the simplifications of the method, one can acknowledge the outcome to be consistent with experimental data. Calculations show that an apparently preferred position for the carbon atom adsorption is that on the reconstructed surface below the iron atom. This should be taken into account in a future study on $\mathrm{Fe}(100) c(2 \times 2)-\mathrm{C}$ structure.

\section{References}

[1] L.A. Bolshov, M.S. Veshchunov, Poverkn., Fiz. Khim. Mekh. (USSR) 7, 5 (1989).

[2] G. Somorjai, M. Van Hove, Prog. Surf. Sci. 30, 201 (1989).

[3] P.A. Dowben, M. Grunze, R.G. Jones, Surf. Sci. 109, L 519 (1981).

[4] F. Bozsa, G. Ertl, M. Grunze, M. Weiss, J. Catal. 49, 18 (1977).

[5] J.W.M. Frenken, J.F. van der Veen, G. Allan, Phys. Rev. Lett. 51, 1976 (1983).

[6] D.T.Vu Grimsby, Y.K. Wu, K.A.K. Mitchell, Surf. Sci. 232, 51 (1990).

[7] B. Voigtländer, S. Lehwald, H. Ibach, Surf. Sci. 225, 162 (1990).

[8] H.D. Shih, F. Jona, Surf. Sci. 60, 445 (1976).

[9] M.J. Pellin, C.E. Young, D.M. Gruen, Y. Aratono, A.B. Dewald, Surf. Sci. 151, 477 (1985).

[10] C. Somerton, D.A. King, Surf. Sci. 89, 402 (1979).

[11] B. Chakraborty, S. Holloway, J.K. Norskov, Surf. Sci. 152/153, 660 (1985).

[12] W. Arabczyk, H.-J. Mussig, Vacuum 37, 137 (1987).

[13] W. Arabczyk, H.-J. Mussig, Acta Univ. Wratislav. 1025, 37 (1988).

[14] T.J. Raeker, A.E. DePristo, Surf. Sci. 235, 84 (1990).

[15] M.W. Ribarsky, Solid State Commun. 38, 935 (1981).

[16] S.R. Chubb, W.E. Pickett, Phys. Rev. Lett. 58, 1248 (1987).

[17] H. Huang, J. Hermanson, Plys. Rev. B 32, 6312 (1985).

[18] K.O. Legg, F. Jona, D.W. Jepson, P.M. Marcus, Phys. Rev. B 16, 5271 (1977).

[19] J.M. van Zoest, J.M. Fluit, T.J. Vink, B.A. van Hassel, Surf. Sci. 182, 179 (1987).

[20] W. Arabczyk, E. Rauschke, F. Storbeck, J. Electron Spectrosc. Relat. Phenom. 53, 107 (1990).

[21] W. Arabczyk, E. Rauschke, F. Storbeck, Surf. Sci. 247, 264 (1991). 
[22] R. Hoffmann, J. Chem. Phys. 39, 1397 (1963).

[23] H.J. Grabke, W. Paulitschke, G. Tauber, H. Viefhaus, Surf. Sci. 63, 377 (1977).

[24] J.B. Benziger, R.J. Madix, J. Electron Spectrosc. Relat. Phenom. 20, 281 (1980).

[25] T.J. Vink, O.L.J. Gijzeman, J.W. Geus, Surf. Sci. 150, 14 (1985).

[26] G. Ertl, M. Grunze, M. Weiss, J. Vac. Sci. Technol. 13, 314 (1976).

[27] M. Grunze, F. Bozso, G. Ertl, M. Weiss, Appl. Surf. Sci. 1, 241 (1978).

[28] J.P. Lu, M.R. Albert, C.C. Clang, S. Bernasek, Surf. Sci. 227, 317 (1990).

[29] J.P. Lu, M.R. Albert, S. Bernasek, Surf. Sci. 215, 348 (1989), and the references included there.

[30] R. Imbihl, R.J. Behm, G. Ertl, W. Moritz, Surf. Sci. 123, 129 (1982). 